OPEN ACCESS

Edited by: Ger Rijkers, University College Roosevelt,

Netherlands

Reviewed by: Jan Tuckermann,

University of UIm, Germany Alexandra K. Kiemer, Saarland University, Germany

*Correspondence: John A. Cidlowski cidlows1@niehs.nih.gov

Specialty section: This article was submitted to Autoimmune and Autoinflammatory Disorders, a section of the journal

Frontiers in Immunology

Received: 19 February 2021 Accepted: 05 May 2021 Published: 17 May 2021

Citation:

Diaz-Jimenez D, Kolb JP and Cidlowski JA (2021) Glucocorticoids as Regulators of MacrophageMediated Tissue Homeostasis.

Front. Immunol. 12:669891. doi: 10.3389/fimmu.2021.669891

\section{Glucocorticoids as Regulators of Macrophage-Mediated Tissue Homeostasis}

\author{
David Diaz-Jimenez, Joseph P. Kolb and John A. Cidlowski * \\ Molecular Endocrinology Group, Signal Transduction Laboratory, National Institute of Environmental Health Sciences, \\ National Institutes of Health, Research Triangle Park, NC, United States
}

Our immune system has evolved as a complex network of cells and tissues tasked with maintaining host homeostasis. This is evident during the inflammatory responses elicited during a microbial infection or traumatic tissue damage. These responses seek to eliminate foreign material or restore tissue integrity. Even during periods without explicit disturbances, the immune system plays prominent roles in tissue homeostasis. Perhaps one of the most studied cells in this regard is the macrophage. Tissue-resident macrophages are a heterogenous group of sensory cells that respond to a variety of environmental cues and are essential for organ function. Endogenously produced glucocorticoid hormones connect external environmental stress signals with the function of many cell types, producing profound changes in immune cells, including macrophages. Here, we review the current literature which demonstrates specific effects of glucocorticoids in several organ systems. We propose that tissue-resident macrophages, through glucocorticoid signaling, may play an underappreciated role as regulators of organ homeostasis.

Keywords: glucocorticoids, macrophages, homeostasis, glucocorticoid receptor, inflammation

\section{INTRODUCTION}

For over 70 years, synthetic glucocorticoids have been used to treat numerous inflammatory conditions, including allergies, asthma, autoimmune diseases, sepsis, and cancer. This is partially due to their profound ability to modulate the immune response through anti-inflammatory and immunosuppressive mechanisms. Endogenous glucocorticoids (such as cortisol in humans and corticosterone in mice) are a class of adrenal cortex steroid hormones regulated through the hypothalamic-pituitary-adrenal axis. They are produced in response to stresses such as infection, but are also naturally secreted in circadian and ultradian cycles. Cortisol acts as a biochemical signaling molecule and is involved in numerous metabolic processes in the body. However, cortisol deficiency in the body leads to an exacerbated inflammatory response. Furthermore it is well recognized that the serum level of cortisol in the body is decreased in the elderly.

Both endogenous and synthetic glucocorticoids (dexamethasone and prednisone, among others) exert their therapeutic effects primarily through the glucocorticoid receptor (encoded by NR3C1, hereafter GR), and their efficacy in controlling inflammatory conditions results from the pleiotropic effects of the GR signaling pathways (1). GR is a member of the nuclear receptor superfamily and is a 
ligand-dependent transcription factor. It is expressed ubiquitously in almost every human cell, including all immune cells (2). When bound by its ligands, GR translocates to the nucleus and occupies specific palindromic DNA sequences within the open chromatin, called glucocorticoid response elements (GREs), to activate or repress gene expression (3-8). GR activates gene expression through different mechanisms that involve direct binding of dimers to GREs within GR-binding sites or composite binding in which GR and another transcription factor interact with distinct response elements within the same genome location. For example, glucocorticoids enhance phosphoenolpyruvate carboxykinase gene expression through GR and CREB binding to GREs and a cyclic AMP response element, respectively, within close proximity (9).

Glucocorticoid-mediated gene repression or GR transrepression occurs through direct binding of GR to repressive DNA motifs (negative glucocorticoid response elements or nGREs) $(10,11)$ or tethered recruitment of ligand-bound GR to another transcription factor without DNA interaction. Tethering is likely the most studied mechanism for immune regulation by glucocorticoids. Many studies have linked this mechanism to the beneficial antiinflammatory actions of glucocorticoids $(12,13)$. Tethering occurs when GR binds to another transcription factor without interacting with DNA. GR has been shown to tether key pro-inflammatory transcription factors, including nuclear factor- $\kappa \mathrm{B}(\mathrm{NF}-\kappa \mathrm{B})$ and activator protein 1 (AP-1), which antagonizes their interaction with chromatin, influences the recruitment of co-regulators, and results in gene expression inhibition. Remarkably, using genomewide profiling in LPS activated macrophages upon Dex treatment, Uhlenhaut et al. found that $20 \%$ of GR-dependent repression is related to nGREs and tethered sites, suggesting that the positive and negative GR cistromes are predominantly composed of classical GREs in close proximity to NF-kB and AP-1 binding sites (6).

Interestingly, $\mathrm{GR}^{\mathrm{dim}}$ mice carrying an amino acid substitution (A465T) in the D-loop of the DNA-binding domain of GR showed reduced, but not completely absent, transactivation ability in response to glucocorticoids (14), suggesting that the GR dimerization-dependent gene regulation was not essential for the effects of GCs. Direct binding of GR as monomers also has been described $(5,15)$. Initially, the mechanism of transrepression proposed that the monomeric state of GR repress the transcription by tethering to DNA-bound TFs (10, 11). Using mouse liver from $\mathrm{WT}$ and $\mathrm{GR}^{\mathrm{dim}}$ under endogenous corticosterone exposure and chromatin immunoprecipitation with lambda exonuclease digestion and sequencing (ChIPexo), Lim HW et al., reported that monomeric GR interaction with a half-site motif is more prevalent than homodimer binding (5). This monomeric GR interaction with a half-site motif display greater cell-type specificity and enrichment for lineagedetermining TFs relative to dimer sites. These data arguing in favor of a model termed half-site-facilitated tethering, where sequence-specific interaction of GR monomers to different motifs promotes transient contacts between monomers and nearby TFs (5).

The GR has been previously reported to modify chromatin structure as well (16-18). New evidence establish that glucocorticoids exert primary repressive effects on transcription through altering chromatin structure (18). For example, using a global run-on sequencing or GRO-seq, Sasse et al., demonstrated that the repression of many TNF-regulated genes and enhancers by dex treatment rapidly changes the chromatin structure in a process that does not required GR occupancy (18). This evidence suggest that either a transrepressive or nGRE mechanisms on the NF-kB signaling are not implicated. Moreover, the high resolution given by GRO-seq also allowed to discover a secondary anti-inflammatory effects resulting from transcriptional cooperation between GR and $\mathrm{NF}-\mathrm{kB}$ at a subset of regulatory regions (18). This cooperative glucocorticoid-TNF crosstalk in the repression of inflammatory processes previously was observed by Vettorazzi et al. in a model of acute lung inflammation (7), where Dex and pro-inflammatory stimuli in macrophages, synergistically via GR increased sphingosine1-phosphate (SphK1) expression and the levels of S1P circulating that play a role in attenuating lung inflammation. These data provide evidence that reducing the expression of proinflammatory cytokines, a classic feature of glucocorticoids treatment, is not sufficient to resolve the inflammation.

Glucocorticoids do not only antagonize proinflammatory gene expression. They have recently been shown to induce proinflammatory gene expression in several cell types, including macrophages (19-21). For example, dexamethasone upregulated expression of the NLRP3 inflammasome in human THP-1 macrophages, causing them to be more responsive to the NLRP3 agonist ATP (19). In addition, co-regulation of genes by glucocorticoids and cytokines has been demonstrated in which glucocorticoids and cytokines synergize to enhance proinflammatory mediator production (20). Finally, GRmediated induction of exopeptidase DPP4 contributed to the increased mobility of macrophages in response to dexamethasone (21). However, the extent of this co-regulation and its mechanism in immune cells is poorly understood.

Macrophages are innate immune system effector cells which, upon inflammation, phagocytose apoptotic and necrotic cells. They are involved in tissue repair and modulate inflammation by balancing pro- and anti-inflammatory responses. Interestingly, glucocorticoids seem to have limited efficacy in the control of inflammation in diseases related to macrophage activity, such as, atherosclerosis, ulcerative colitis and respiratory tract diseases $(22,23)$. While it is true that many of the diseases mentioned above are quite successfully controlled by corticosteroids treatment, this has been associated to early stages of the diseases because they are able to inhibit many components of the inflammatory response. Even in the clinical management of some of them, the use of corticoisteroids has been recommended as adjunct treatment at the lowest dose possible and for the shortest time possible. Although glucocorticoids induce cell death and reduce cell survival in immune cells such as $\mathrm{T}$ and $\mathrm{B}$ cells, macrophages are relatively resistant to glucocorticoidinduced apoptosis (2). These observations support the idea that the pro-inflammatory versus the anti-inflammatory regulatory actions of glucocorticoids may be predominant in macrophages.

The macrophage ontogeny has been challenged during the last two decades. The paradigm that tissue-resident macrophages 
are continuously replenished by blood-circulating monocytes, which arose from bone marrow (BM)-derived precursors was updated since Merad et al, showed that Langerhans cells, a kind of macrophages in the skin, were resistant to the irradiation and were not derived from donor after congenic BM transplanstation (24). The current models of macrophage ontogeny have been established through genetic fate-mapping techniques. For example, now is well-known that major tissue-resident macrophage populations, including microglia, liver Kupffer cells, lung alveolar macrophages, epidermal Langerhans cells and splenic macrophages, are established during the embryogenesis from the yolk sac (YS) anf fetal liver and subsequently maintain themselves independently of replenishment by blood monocytes during adulthood (25, 26). Contrary, macrophages population from the gut and heart are constantly replenished by blood monocytes postnatal $(27,28)$. In the new era of "omics" techniques, single-cell RNA-sequencing have revealed a next level of complexity to the functional heterogeneity of the embryonic origin of key tissue-resident macrophage populations. For example, depth analysis of arterial macrophages at single-cell resolution in steady state and in response to angiotensin-II (AngII)induced arterial inflammation revealed dual origin of arterial macrophages from both YS and BM-hematopoiesis, a process that is stable in adult mice, but declines in numbers during ageing and is not replenished by bone marrow (BM)-derived macrophages (29). In AngII inflammation, BM-derived macrophages invade the inflamed adventitial tissue, while resident -YS erythromyeloid progenitors (EMP)-derived macrophages- were self-renewal and proliferate locally providing a distinct transcriptional profile linked to tissue regeneration (29). Despite the fact that our understanding of ontogeny of macrophages is increasing, the precise developmental trajectories of tissue-resident macrophages remain undetermined.

Another level of complexity into the macrophages biology is given by the activation or polarization processes. Macrophages are polarized according to changes in their environment and are classically divided in two main categories, M1 macrophages and M2 macrophages (30). M1 macrophages are mainly involved in pro-inflammatory responses, classically generated upon induction by microbial products, such as LPS and pectidoglycan and pro-inflammatory cytokines such as interferon-gamma. M2 macrophages are mainly involved in anti-inflammatory responses, ultimately associated with promoting wound healing, tissue repair and for resolving inflammation $(31,32)$. Glucocorticoids have been related to a M2like phenotype, where the capacity to promote tissue repair and wound healing has been demonstrated (33-35). However, the direct participation of GR in the polarization still are not as well-understood.

Macrophages play a critical role in determining the extent of our body's inflammatory response. However, macrophage function becomes impaired with increasing age and this could be linked to an imbalance between the amount of cortisol generated and the increase in the quantities of pro-inflammatory molecules produced in the body. Recently, has been proposed that low levels of the stress hormone cortisol and loss of the glucocorticoid-induced leucine zipper (GILZ) expression in macrophages can trigger chronic inflammatory responses in the body, contributing to the aging process (36).
Here, we review mechanisms whereby glucocorticoids can regulate physiological tissue homeostasis through the macrophage as a sensor, with emphasis on tissues where glucocorticoid signaling has been ablated using specific GR knockout mouse models. We propose that the pro-inflammatory or positive gene regulatory actions of glucocorticoids on macrophages may be a way in which macrophages shape the physiology of tissues.

\section{GLUCOCORTICOIDS IN THE IMMUNE- SURVEILLANCE OF THE HEART}

Glucocorticoid signaling has direct effects during cardiac development and in both physiological and pathological conditions of the cardiovascular system. Multiple studies have revealed an important role for circulating glucocorticoids in the regulation of heart function and in impaired infarct healing, but they have not discriminated between direct and systemic actions of these hormones (37). By generating mice lacking GR expression solely in heart tissue (the cardiomyocyte-specific GR knockout or cardioGRKO), our group found that mice died prematurely from pathological cardiac hypertrophy that progressed to dilated cardiomyopathy and heart failure (38). It is established that endogenous glucocorticoids can also signal through the closely related mineralocorticoid receptor (encoded by $\mathrm{Nr} 3 \mathrm{c} 2$, hereafter MR). For example, Oakley et al. generated mice lacking both GR and $\mathrm{MR}$ in cardiomyocytes which were resistant to cardiac disease in comparison to cardioGRKOs (39). Interestingly, these findings suggest that an appropriate amount of glucocorticoid signaling through both GR and $\mathrm{MR}$ in cardiomyocytes is critical for maintaining a healthy heart.

Heart failure is one of the leading causes of morbidity and mortality. It is recognized that innate immune cell activation occurs in patients with heart failure. This activation is associated with adverse clinical outcomes for disease progression. While it is accepted that neutrophils produce robust inflammatory responses and contribute to heart damage after acute ischemic injury, macrophages improve healing and cardiac remodeling after injury by promoting neutrophil efferocytosis, suppressing free radical formation, and modulating fibroblast activation state; however, the exact roles played by macrophages continue to be explored and defined (40-42). Paradoxically, macrophages can also trigger a damaging inflammatory response, which was shown in a zebrafish model where macrophages directly contributed to fibrosis during heart repair (43).

It has been suggested that distinct macrophage populations, such as resident or recruited subsets, may favor healing of injured areas or promote inflammatory and reparative functions (44). In the heart, tissue-resident macrophages populate different regions, including the ventricular myocardium, where they are found throughout myocardial interstitial spaces and interact directly with capillary endothelial cells and cardiomyocytes (45). They are also found in the atrioventricular node, where they facilitate electrical conduction by coupling to cardiomyocytes through 
connexin 43-containing gap junctions (46). Recently, NicolasAvila et al, demonstrated that macrophages can clean up dysfunctional mitochondria from cardiomyocytes, helping to maintain cardiac health and homeostasis (47). These data suggest broader homeostatic functions for heart resident macrophages; therefore, macrophages are an emerging target for therapeutic strategies aimed at minimizing cardiomyocyte death, ameliorating pathological cardiac remodeling, and treating heart failure after myocardial infarction.

Glucocorticoids play key roles in the regulation of macrophage homeostatic functions and in their functional properties to resolve inflammation and tissue damage (22). The loss of glucocorticoidmediated regulation of macrophage function in the heart could result in the dysregulation of factors that control inflammation, neovascularization, collagen degradation, and scar tissue formation. In a model of myocardial infarction, mice lacking GR in myeloid cells under control of lysozyme M locus (LysM) promoter die earlier after infarction than wild type controls. GR-deficient macrophages were shown to exacerbate cardiac remodeling and to cause impairment of collagen scar formation and angiogenic response to ischemic injury, resulting in dysregulation of the resolution of inflammation and defects in wound healing (34).

Finally, the newly discovered macrophage function related to the active elimination of cardiomyocyte-derived mitochondria through the phagocytic receptor Mer tyrosine kinase (Mertk) (47) reinforces the idea that glucocorticoids contribute to cardiac tissue homeostasis (Figure 1). It's established that glucocorticoids upregulate Mertk expression in macrophages (48) and promote the phagocytosis of apoptotic neutrophils (49). The clearance of apoptotic cells and dysfunctional mitochondria by macrophages ensures mitochondrial and cardiomyocyte fitness, tissue proteostasis, and cardiac function. Therefore, glucocorticoids acting through macrophages could determine the balance between cardiac immunity and tolerance. Failure of this mechanism caused by defects in cardiac macrophage sensing of glucocorticoids, rather than from age related impairment of cardiomyocytes, could compromise cardiac homeostasis and promote heart disease.

\section{GLUCOCORTICOIDS IN THE IMMUNE- SURVEILLANCE OF THE CENTRAL NERVOUS SYSTEM}

The central nervous system (CNS) is a prominent target of glucocorticoids because GR is ubiquitously expressed in neurons, glial cells (such as astrocytes, oligodendrocytes and microglia) (50-53) in addition to brain vasculature (54). Moreover, differential expression of the glucocorticoid receptor has been described in specific subregions of the human cortex such as the basolateral amygdala, CA1 hippocampus and dentate gyrus. Glucocorticoid effects on the brain are related to the adaptation to stress. They primarily depend on GR distribution and functional pattern, and vary with gender, age, hormone concentrations, timing, and duration of exposure (55). There is compelling evidence for direct GC effects on behavior, cognition and $\operatorname{mood}(56,57)$. At the cellular level, glucocorticoids are necessary for neuronal growth and differentiation. They also have an impact on several neuronal functions, including cell survival, integrity, and synaptic plasticity $(58,59)$. In humans and rodents, it has been described that glucocorticoids play a role in both embryonic and adult neurogenesis (60). Similar to embryonic development, neurogenesis in the adult happens in the hippocampus and involves a multi-step process starting with the division of neural stem cells and subsequent maturation into neural progenitor cells, proliferation of progenitor cells, maturation, morphological changes, migration, physiological adaptation, and functional integration into the hippocampal network (61). Newly generated neurons in the hippocampus contribute to learning and memory (62), forgetting (63) and cognitive flexibility (64). Interestingly, chronically elevated glucocorticoid levels under prolonged exposure to stress has been related to changes in the hippocampal cytoarchitecture, such as atrophy of dendritic processes and inhibition of neurogenesis $(65,66)$. Hippocampal neurons also play an essential role in the negative feedback regulation of the HPAaxis (67). Consequently, impaired hippocampal neurogenesis is closely associated with brain disorders and neurodegeneration by disrupted hypothalamic-pituitary axis functions. Interestingly, Quarta C., et al. (68), developed a tissue-specific antiinflammatory drug that conjugate glucagon-like peptide-1 (GLP-1) to dexamethasone (GLP-1/Dexa) to selectively delivers dexamethasone to GLP-1 receptor (GLP-1R)-expressing cells (68). They showed that GLP-1/Dexa ameliorates the dietinduced systemic inflammation and does not induce negative effects on HPA-axis activity however, they do not deepen into the identity of the GLP-1R-expressing cells (68). Some studies have shown that macrophages could be one of the cells responding to the drug because they also express $\operatorname{GLP}-1 \mathrm{R}(69,70)$. In addition, we recently published that dexamethasone induced the expression of the exopeptidase DPP4 that is recognized as one of the most important inactivator of GLP1 (21).

Glucocorticoids also play a crucial role in regulation of the immune system and intermediate metabolism within the brain. By inhibiting the immune system, glucocorticoids prevent overproduction of inflammatory molecules that can be harmful to neurons. The most notable CNS immune cells affected by glucocorticoids are the microglia. As resident macrophages of the nervous system, microglia are the brain's professional phagocytes that sense and coordinate the brain inflammatory response. Microglia are the predominant immune cells of the CNS, comprising approximately $10-12 \%$ of the cells in the brain, with higher numbers within the hippocampus (71). Microglia normally exist in a quiescent or "resting" state in the healthy adult brain and, in response to tissue injury or disease, can transform rapidly from a quiescent state to different activation states (72). They are highly motile cells that survey the local environment and release cytokines that coordinate the response of both innate and adaptive immunity to control infection, remove cell debris and promote tissue repair (73). Upon activation, microglia upregulate cell surface molecules 


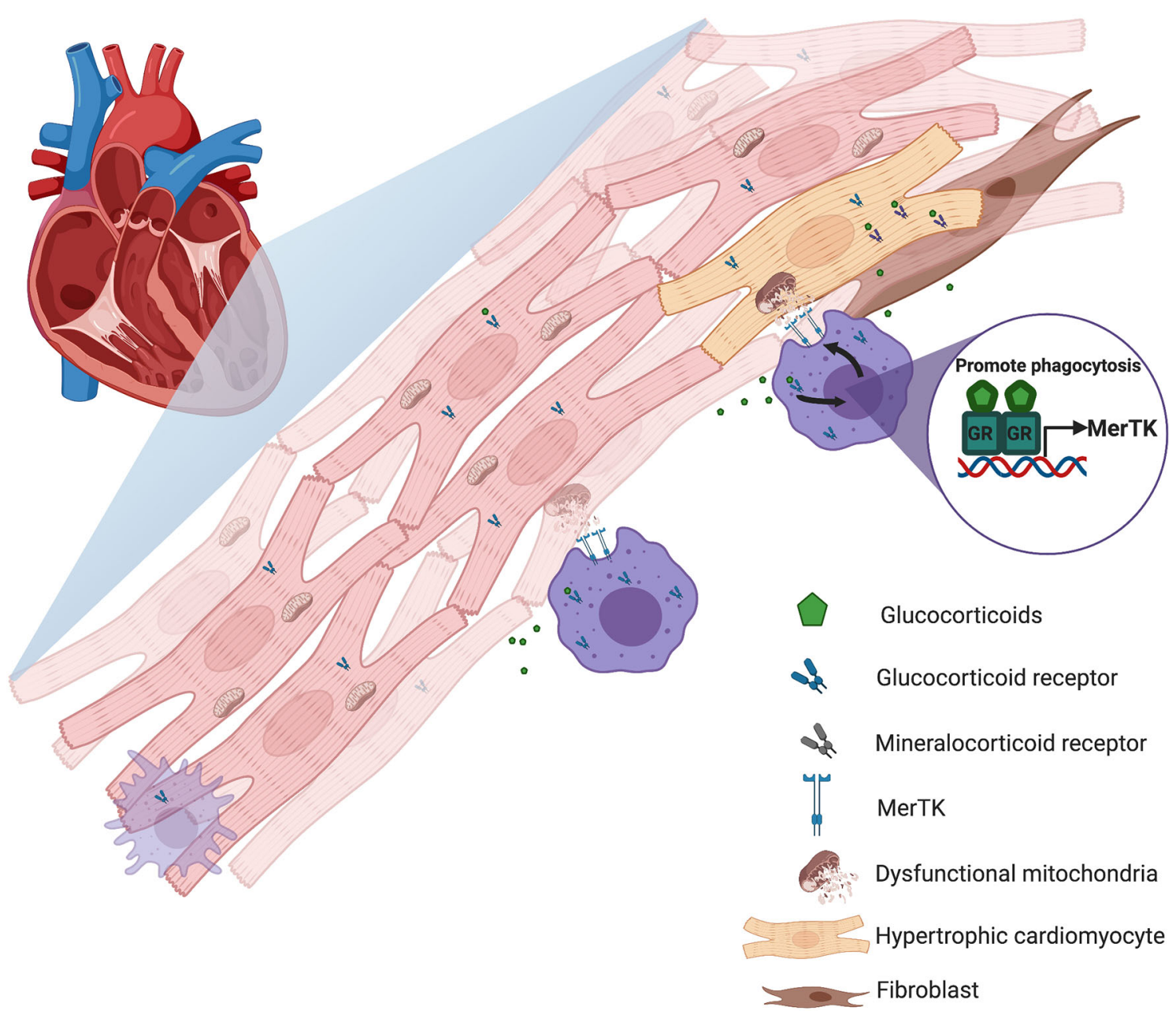

FIGURE 1 | Schematic representation of how glucocorticoids could contribute to cardiac tissue homeostasis. Upon damage or stress activation, glucocorticoidactivated cardiac macrophages promote the active elimination of hypertrophic cardiomyocyte-derived mitochondria and help maintain cardiac health and homeostasis through the induction of the phagocytic receptor Mer tyrosine kinase (Mertk).

including major histocompatibility complex class I and II, receptors for cytokines and chemokines, such as CD200R (74) and CX3CR1 (75), and several other cellular markers indicative of increased reactivity (76). The constitutive expression of HLADR in human microglia has been related to their immunesurveillance of the brain (77). Recently, it has been described that microglial mTOR-dependent metabolic flexibility and glutaminolysis support their effector functions within the brain parenchyma (78).

In addition to their roles as immune sentinel cells, microglia also play a direct role in the regulation of neuron networks and physiology. Microglia can produce factors that modulate proliferation or survival of neurons $(79,80)$. Consistent with the well-known microglia functions as a sensors and phagocyte cells, Wang et al. (81), demonstrated that microglia eliminate synaptic components in the adult hippocampus, leading to dissociation of engram cells and the forgetting of previously learned contextual fear memory in a complement- and activitydependent manner.

Conditions that are commonly associated with microglial activation and inflammation in the brain, such as aging, chronic stress, and neurodegenerative diseases also affect adult hippocampal neurogenesis (82). Mechanisms of immune regulation in the CNS are largely dependent on neuronal viability and activity, so the interactions between neurons and microglia are essential in maintaining brain homeostasis (83). Recently, Diaz-Aparicio et al. (84) showed that microglia also modulate adult hippocampal neurogenesis through the secretome associated with phagocytosis of apoptotic newborn cells via purinergic P2Y12 receptor and MerTK. As we discussed above for heart immunosurveillance, glucocorticoids could also regulate the expression of MerTK on microglia and promote the long-term homeostasis of adult hippocampal neurogenesis (Figure 2). 


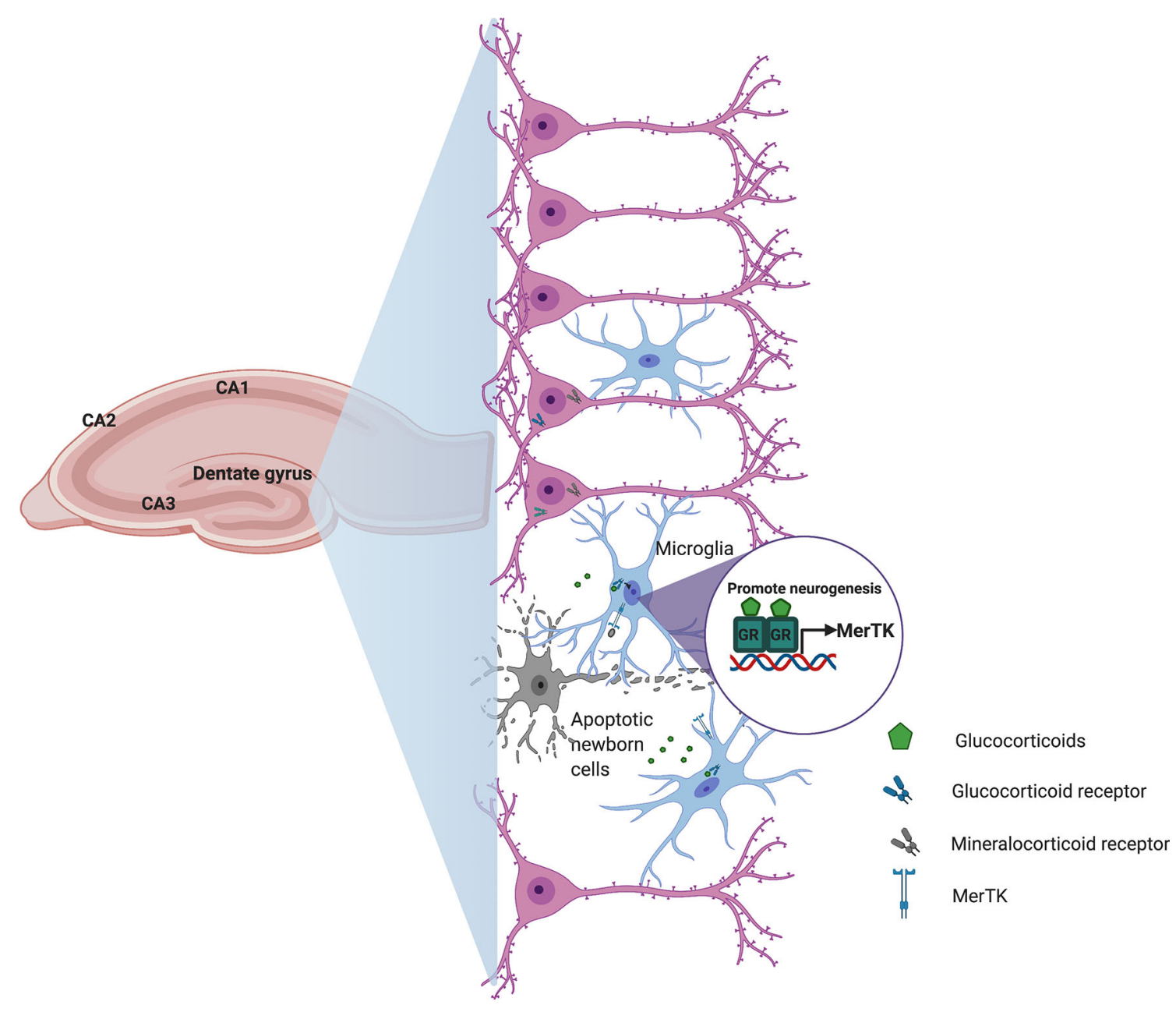

FIGURE 2 | Schematic representation of how glucocorticoids could contribute to central nervous system homeostasis. During hippocampal neurogenesis, cell debris derived from apoptotic newborn cells and stress-induced glucocorticoid secretion promote microglia activation and transcriptional induction of the phagocytic receptor Mertk to regulate the production of new neurons in order to maintain homeostasis in the adult hippocampal neurogenic niche.

The CNS is highly sensitive to damage and any inflammatory response occurring within this organ system must be regulated. Microglial activation, and subsequent suppression, is necessary for host defense and neuroprotection following insult. However, these microglial neuromodulatory mechanisms may become deficient and/or dysregulated under excessive or prolonged inflammatory stimulation induced by stress, disease, and injury (71). One proposed mechanism for maintaining control of microglial activation is through their interaction with neuronal signaling molecules. Healthy neurons maintain microglia in their resting state via secreted and membrane bound signals, including CD200, CX3CL1 (fractalkine), neurotransmitters and neurotrophins $(83,85)$. A reduction in these regulatory factors can lead to microglia hyperactivation, suggesting an important role for communication between neurons and microglia in regulating neuroinflammation.

Although it has been known that glucocorticoid signaling is required for proliferation, differentiation, and survival of neurons, it appears to also be a critical regulator of microglia immunosuppression. By inhibiting microglial activation, glucocorticoids may have opposite effects in changing the immune status of the brain and may make neurons more susceptible to damage. In contrast, studies have suggested that GR activation in microglia promotes their neuroprotective function $(86,87)$. For example, GR-deficiency in microglia exacerbated neuronal and axon damage caused by intraparenchymal injection of LPS, and GR signaling in microglia suppresses stress-induced neuronal death (86). Interestingly, Maatouk et al. demonstrated that the number of microglia-expressing GR was significantly reduced in the brain of post-mortem Parkinson's disease subjects compared to control tissue and also observed a significant upregulation of TLR9 protein (87). Moreover, in two mice model lacking GR in microglia/ macrophages (GRLysM ${ }^{\text {cre }}$ and GRCX3CR1 ${ }^{\text {CreER2 }}$ GR mutant mice), intranigral injection of CpG-ODN (TLR9 ligand), resulted in significant loss of dopamine neurons in the brain (87). Although is well known that glucocorticoids are key regulators of TLRs activation upon inflammation, these data suggesting that the loss 
of GR in microglia also could contribute to dopamine neurodegenerative process. While both increased microglia activation and neuronal injury can be the result of an exaggerated neuroimmune response, it is unknown if microglial overactivation precedes and causes neuronal damage, or if activation occurs in response to loss of normal neuronal integrity. The differential and separate effects of glucocroticoids on neurons and microglia might depend on the machinery each type of cell possesses, the timing of exposure (before, during, or after activation) and the way they ultimately integrate permissive, preparative, suppressive, and stimulatory effects.

\section{GLUCOCORTICOIDS IN THE IMMUNE- SURVEILLANCE OF THE GASTROINTESTINAL TRACT}

The gastrointestinal (GI) tract represents the largest interface between the organism and the external environment. The GI tract is persistently exposed to a high antigenic load derived from the dense, but largely harmless, commensal microbiota. Because of the mutualistic relationship between microbiome and host, the GI tract establishes a delicate coupling of immune resistance to pathogens and tolerance to tissue damage and inflammation. An important player in this process is the tissue macrophage. Intestinal macrophages, which function as phagocytes, are crucial to maintain the homeostasis of normal healthy GI tract tissues, but are also important for protection against pathogens through the secretion of pro-inflammatory mediators. Intestinal macrophages are also involved in the repair of damaged tissue through the production of proteins that drive epithelial cell renewal (88-90). Tissue-resident macrophages in the steady state are strongly influenced by the microbiota, and major populations are distributed in the stomach as well as along the length of the small and large intestines $(91,92)$. Unlike many other tissue macrophages, those in the mucosa of the GI tract are derived by continuous but distinct replenishment rates from circulating monocytes $(27,93)$. Interestingly, a new population of self-maintaining macrophages that are closely positioned in the intestinal submucosa and muscularis externa and arise from both embryonic precursors and adult bone marrow-derived monocytes, persists throughout adulthood and promotes intestinal homeostasis (94). At the functional level, these self-maintaining macrophages control intestinal physiology by supporting the vascular architecture, the permeability, and the intestinal motility that regulates neuronal function in the myenteric plexus (94).

The important role of resident gastrointestinal macrophages in maintaining local homeostasis was discovered through a study by Zigmond et al. (95), where mice harboring IL-10 receptor alpha subunit (IL10RA) deficiency failed to sense interleukin-10 (IL-10; a pleiotropic and anti-inflammatory cytokine produced by $\mathrm{T}$ cells, $\mathrm{B}$ cells, and macrophages upon inflammation), resulting in spontaneous development of severe colitis. In a mouse model of inflammatory bowel disease (IBD), a chronic inflammatory disorder of the GI tract, mice lacking GR in myeloid cells (GRlysM) displayed impaired disease resolution to dextran sulfate sodium (DSS)-induced colitis and a diminished expression of IL-10 (35). The defect in the acquisition of an antiinflammatory status and the lack of tissue repair caused by GR ablation in myeloid cells was characterized by persisting clinical symptoms and tissue damage, demonstrating an essential role for GR in macrophages for the induction of tissue repair mechanisms after intestinal tissue damage (Figure 3).

Glucocorticoid signaling in the GI tract plays a role in both regulation of the intestinal stress response and intestinal tissue homeostasis. This is suggested by the fact that synthetic glucocorticoid therapy is effective in inducing remission in IBD patients (96). Elevated GC levels as a result of stress or treatment also enhance the nutrient absorption by enterocytes $(97,98)$. Moreover, an increase in gastric acid secretion, induction of gastroparesis or gastric emptying, and the possible formation of gastric ulcers, in addition to enhanced intestinal glucose transport, have been observed after GC treatment (99). In a study using GRvillinCre mice, Reichardt et al. (100) demonstrated that the lack of GR in enterocytes did not protect mice from glucocorticoidinduced gastroparesis, suggesting that this pathology could be mediated directly by GR in the stomach. Moreover, Cipriani et al. demonstrated that proinflammatory macrophages were necessary for the development of gastroparesis in diabetic mice (101), suggesting that glucocorticoid signaling in the epithelium is needed to control macrophages activation.

Therefore, it is conceivable that GC effects on enterocytes might also contribute to the homeostasis of the entire GI tract. The role of glucocorticoid signaling in the stomach was recently investigated by our group through the depletion of circulating glucocorticoids in mice by adrenalectomy (ADX) (102). The lack of systemic endogenous glucocorticoids in mice resulted in the rapid onset of spontaneous gastric inflammation and the appearance of a clinical phenotype of spasmolytic polypeptide expressing metaplasia (SPEM), a precursor of gastric cancer (102). Moreover, the SPEM which developed in ADX mice was prevented by clodronate treatment and within the $\mathrm{Cx} 3 \mathrm{cr} 1$ knockout mouse model, indicating that CX3CR1+ macrophages derived from monocytes are critical mediators of gastric inflammation (102). Intriguingly, the adrenalectomy does not trigger inflammation within another section of the stomach (gastric corpus greater curvature) and neither in other sections of the GI tract, such as ileum and colon (102). Interestingly, both small and large intestinal mucosa have been recognized as site of extra-adrenal glucocorticoid synthesis (103-105). One of the plausible reasons why ADX mice would not develop spontaneous inflammation in the intestine could be the local production of GCs. In order to cope the local stress, GCs would regulate the immune homeostasis, however this hypothesis have not been addressed yet. The nuclear receptor liver receptor homologue-1 (LRH-1, NR5A2) would be essential to regulate the intestinal glucocorticoid synthesis in vivo (104). Moreover, thought 3 different models, human intestinal organoids, humanized murine intestinal organoids, and a humanized murine IBD model Bayrer al. showed that LRH-1 promotes normal intestinal epithelial homeostasis suggesting that this NR can be an important regulator of intestinal tissue integrity 


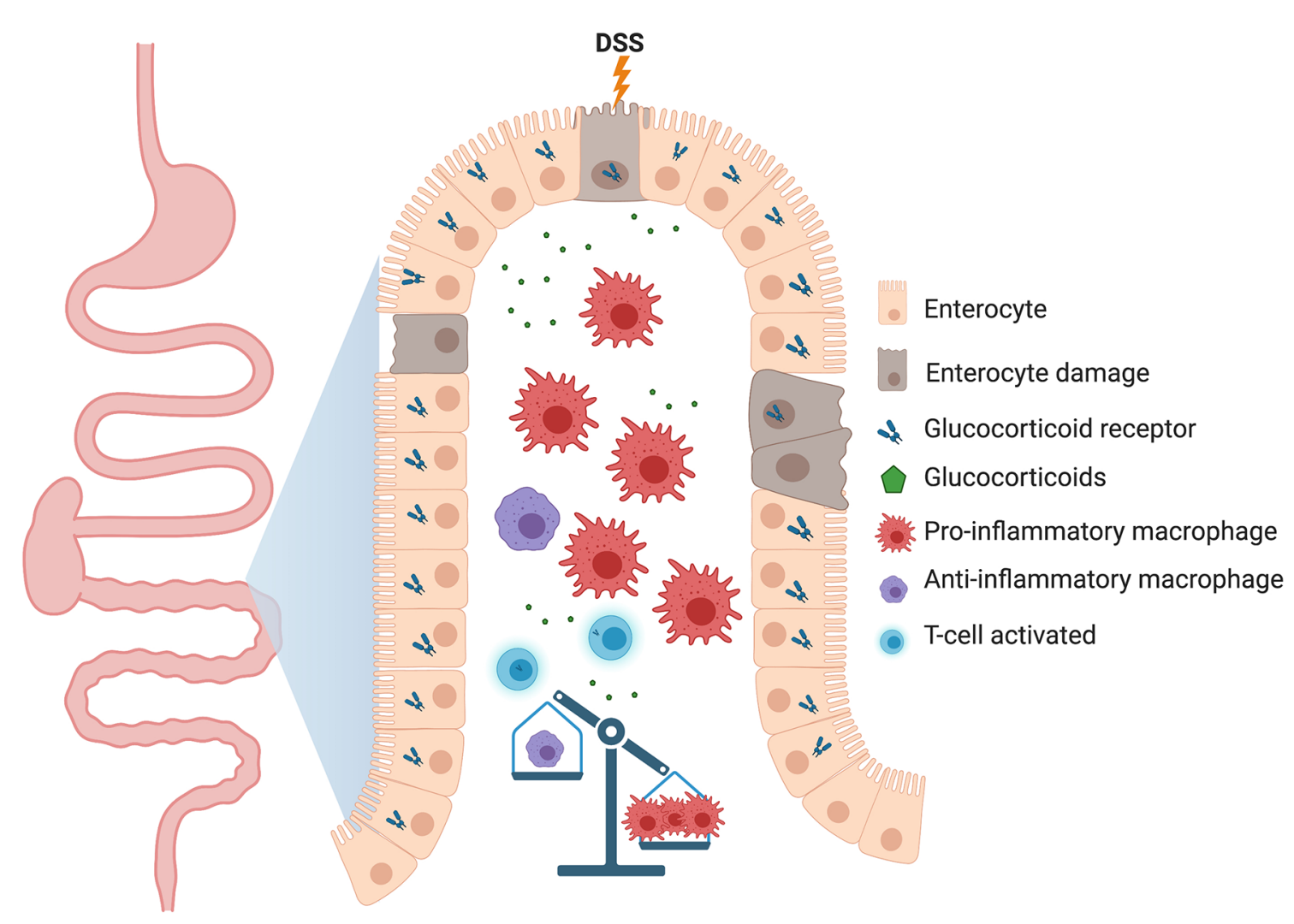

FIGURE 3 | Proposed model of how the lack of glucocorticoid receptor (GR) in macrophages could be detrimental to gastrointestinal tissue homeostasis. In the dextran sodium sulfate (DSS)-induced colitis model, deletion of GR in myeloid cells delays the resolution of inflammation through an increase in the number of proinflammatory macrophages which perpetuates tissue damage. Other immune cells, such as B cells, dendritic cells and ILCs relevant to the intestinal physiology have been deliberately neglected to highlight the function of macrophages.

(105). Summarizing, all these findings indicate that glucocorticoid signaling could participate in the immune-surveillance of the gastrointestinal tract and is a critical mediator of both gastric and intestinal homeostasis.

\section{GLUCOCORTICOIDS IN THE IMMUNE- SURVEILLANCE OF THE LIVER}

As their name suggests, glucocorticoids are profound regulators of glucose metabolism. It is no surprise then that the liver, the organ responsible for controlling glucose levels, is a major target of glucocorticoid action. Glucocorticoids exert permissive effects on glycogen metabolism and stimulate gluconeogenesis through direct regulation of rate limiting enzymes involved in this process, such as PEPCK and G6Pase $(106,107)$.

Studies using liver-specific GR knockout (L-GRKO) mice have demonstrated the many roles played by GR signaling in hepatocytes. The daily rhythmic production of endogenous glucocorticoids coordinate glucose, lipid, and fatty acid metabolism with periods of feeding and fasting $(108,109)$. This coordination is lost in L-GRKO mice, which exhibit fasting hypoglycemia and reduced body weight, which may involve impaired growth hormone signaling $(110,111)$. Our group evaluated the actions of glucocorticoids on hepatic expression of inflammatory genes in male and female L-GRKO mice. Interestingly, in response to pro-inflammatory LPS challenge, deletion of GR reduced the number of inflammatory genes in a sex-specific manner, with female mice exhibiting regulation of more genes than males (112). Therefore, GR signaling influences diverse gene expression programs in hepatocytes, some of which are sexually dimorphic.

In addition to its roles in regulating metabolism, the liver is also an important part of the immune system. It serves as a major filter for the blood coming from the digestive tract and can respond to potential threats such as bacterial toxins and cellular debris.

Hepatocytes release large amounts of immunoregulatory proteins into the circulation that function to eliminate pathogens and finetune innate immunity. These include members of the complement system, acute-phase proteins, LPS signaling regulators, and several iron-metabolism-related proteins (reviewed in (113)). The liver also contains the single largest reticuloendothelial cell network in the body, which is composed of tissue-resident macrophages called Kupffer cells. Kupffer cells are intimately involved in the hepatic response to various toxic insults. They constitute a primary line of defense against invading microorganisms, function as sensors for 
altered tissue integrity, and control immunological tolerance in the liver by providing an anti-inflammatory microenvironment during homeostasis (114). Kupffer cells are largely stationary and adhere to the liver sinusoidal endothelial cells where they are exposed to the contents of the blood. During times of inflammation, the hepatic macrophage pool is expanded by circulating blood monocytes that give rise to monocyte-derived macrophages (115), which have been shown to resemble the transcriptional phenotype of Kupffer cells after lymphocyte choriomeningitis virus infection (116) or after acetaminophen-induced hepatotoxicity (117).

Relatively few studies have explored the role of GR signaling in Kupffer cells and monocyte-derived liver macrophages. Nevertheless, there is good evidence that glucocorticoid regulation of these immune cells may be essential for liver homeostasis. Kupffer cells respond to glucocorticoids by upregulating the antiinflammatory gene Gilz, and mice with macrophage-specific deficiency in GR exhibit more severe obesity-induced liver inflammation (118). In human and mouse, Kupffer cells secrete the immunosuppressive cytokine IL-10 (119). IL-10 deficiency or depletion exacerbates hepatic immune-mediated liver damage and abrogates tolerance induction (120). For example, in the Concanavalin A hepatitis model, which is used to study tolerance induction and immune-mediated hepatitis, Kupffer cell-derived IL10 exerts hepatoprotective and tolerogenic effects through Treg activation (121). Similarly, Kupffer cells interact directly with T cells in response to administration of particulate antigens, causing the expansion of IL-10-expressing Tregs (122). It is well known that IL10 is a glucocorticoid-induced gene $(123,124)$; therefore, glucocorticoid levels may directly influence the inflammatory environment in the liver by modulating Kupffer cell IL-10 expression (Figure 4).

The liver's response to injury is complex and depends upon the interaction of multiple cell types, both parenchymal and nonparenchymal. Paradoxically, Kupffer cells have been implicated in both liver regeneration and fibrosis. They secrete proinflammatory mediators, such as reactive oxygen species, eicosanoids, prostaglandins, and cytokines that induce recruitment of additional inflammatory cells to the liver (125).

Glucocorticoid receptor ligands have been shown to suppress hepatic expression of pro-fibrotic genes, leading to decreased extracellular matrix deposition (126). In addition, GR ligands inhibit immune cell infiltration to the damaged liver, which can exacerbate injury in certain cases. Using models of tissue-specific deletion of GR, Kim et al. (126) demonstrated that GR signaling controls pro-fibrotic gene expression and immune cell infiltration via two cell types. Specifically, GR deletion in Kupffer cells (via LysM-cre) reversed inhibition of immune cell infiltration in response to dexamethasone. GR deletion in hepatic stellate cells (via hGFAP-cre) reversed downregulation of fibrotic gene expression in response to dexamethasone. These studies suggest that GR signaling in Kupffer cells modulates factors involved in cell recruitment to the liver, while GR signaling in hepatic stellate cells modulates fibrosis in response to injury. Other studies have also supported the idea that GR signaling in Kupffer cells promotes liver homeostasis. Direct targeting of dexamethasone to Kupffer cells promoted replenishment of glycogen stores lost during hepatic fibrosis caused by bile duct ligation (127). Interestingly, Rose et al. (128) demonstrated that the use of glucocorticoids completely sustained hepatocyte longevity and improved hepatocyte functionality during the establishment of co-culture conditions between hepatocytes and Kupffer cells. Additional studies are needed to pinpoint the effects of both endogenous and synthetic glucocorticoids on specific cells within the liver and to understand the interaction between these cell types during times of injury and homeostasis.

\section{CONCLUSIONS AND PERSPECTIVES}

Glucocorticoids mediate physiological processes in different tissues and cell types with high specificity to systematically influence behavior and cognition, metabolism, cardiovascular function, and the immune system. Synthetic glucocorticoids are administrated as drugs to treat several inflammatory conditions because of their ability to induce potent anti-inflammatory and immunosuppressive effects that occur due to the repression of pro-inflammatory genes and the activation of anti-inflammatory pathways in immune cells. Whereas restricted inflammation is beneficial, excessive or persistent inflammation could be associated with chronic diseases. The immune regulation process and anti-inflammatory homeostatic mechanisms mediated by glucocorticoids are essential in limiting and resolving the inflammatory process. The balance of pro- and anti-inflammatory pathways plays an important role in maintaining immune homeostasis. In addition to its immunosuppressive functions, GR signaling may regulate cellular metabolism and survival.

The main mechanism of action of GCs on immune cells has been linked to their ability to induce cell death and reduce cell survival through direct genomic effects. GR-regulated genes that are required to drive apoptosis include pro-apoptotic mediators, such as the BH3-protein BIM (BCL2LII), which is activated (129) and the anti-apoptotic BCL2, which is downregulated (130). Nongenomic effects of GR have also been proposed. Interestingly, a second mechanism that could explain the effectiveness of GC regulation of the immune response is the promotion of Treg proliferation directly or indirectly through macrophage activation. Bereshchenko et al. (131) reported that glucocorticoid-induced leucine zipper (GILZ) promotes Treg production and enhance Treg signaling. Macrophages have been shown to possess the potential to induce Treg function to maintain tissue homeostasis, while Tregs can enhance the ability of macrophages to engulf apoptotic cells which promotes resolution of inflammation (132). Disruption of the crosstalk between macrophages and Tregs leads to severe autoimmune disease and chronic inflammation.

The glucocorticoid regulation of local homeostatic mechanisms has been exemplified through the study of tissuespecific GR knockout mice. We still have limited knowledge of how GR-dependent gene expression contributes to the phenotypes of tissue-specific GR knockout mice. Future studies are needed to fully understand how GR signaling is acting in specific tissues and in different disease states. 


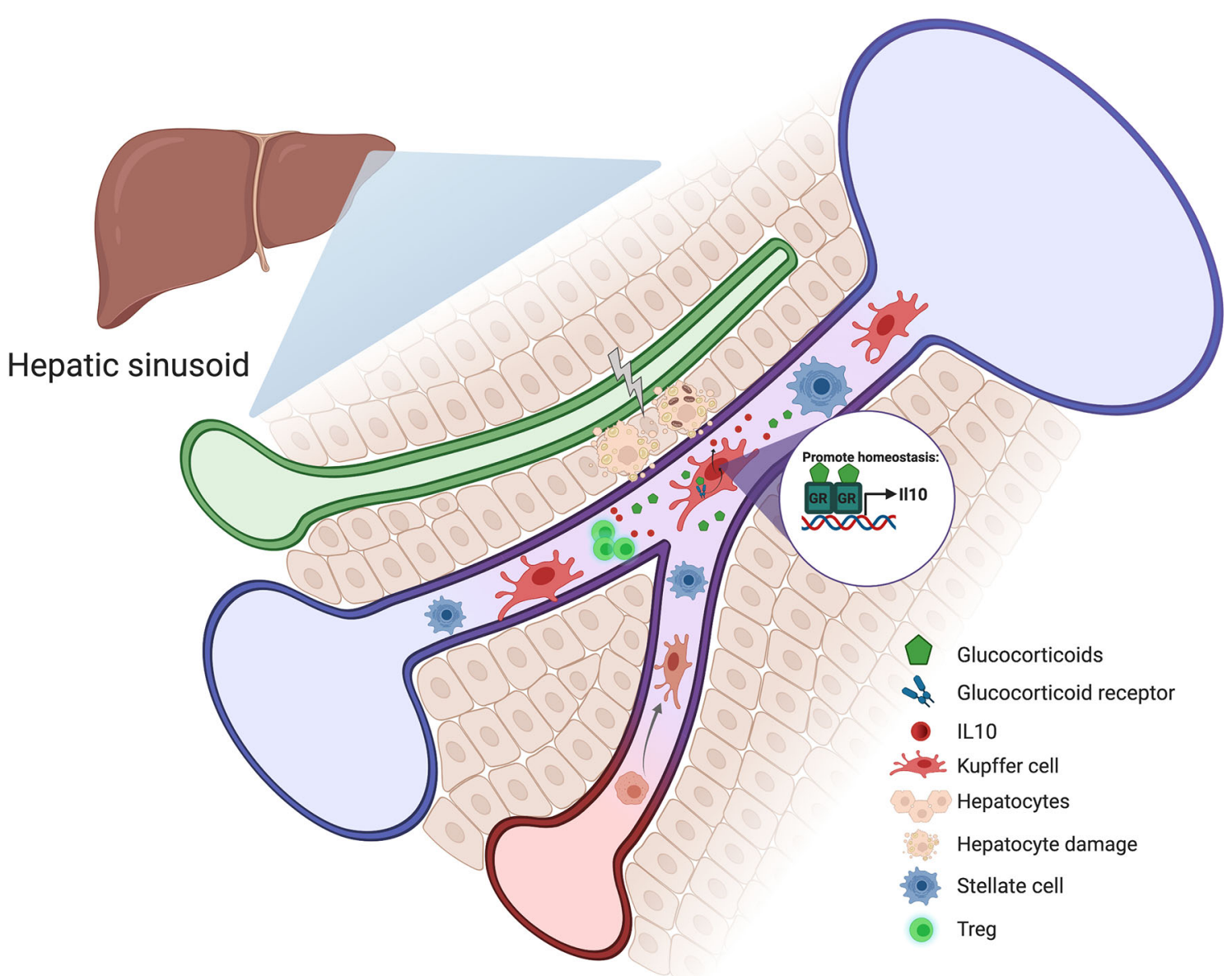

FIGURE 4 | Schematic representation of how glucocorticoids could contribute to liver homeostasis. Stress and hepatocyte injury around the hepatic sinusoid cause an increase in glucocorticoid levels which induces Kupffer cell activation and IL-10 production. Kupffer cell-derived IL-10 exerts hepatoprotective and tolerogenic effects through Treg activation.

Its well-known that glucocorticoids can regulate different stages of macrophage biology, including differentiation, survival, movement, activation and polarization. While it has been long believed that tissue macrophages were originated from myeloid cells and circulating adult blood monocytes, it is now clear that many resident tissue macrophages are established during embryonic development and persist by self-renewal. Even, we now know that multiple populations of macrophagelike cells co-exist in both, steady-state and inflammation. Moreover, under inflammatory conditions, the macrophage pool is expanded by pro-inflammatory infiltrating blood monocytes that may or may not acquire the phenotype of the resident macrophages in a given tissue. Whether glucocorticoids can regulate the gene expression profile of macrophages independently of their ontogeny, activation or polarization states is one of the most important questions that must be addressed. Uncovering distinct glucocorticoid-mediated gene expression networks in macrophages may aid in the production of targeted therapies for diseases characterized by dysregulation of homeostasis.

\section{AUTHOR CONTRIBUTIONS}

DD-J and JK wrote the manuscript with supervision from JC. All authors contributed to the article and approved the submitted version.

\section{FUNDING}

This work was supported by the Intramural Research Program of the NIEHS, National Institutes of Health (1ZIAES090057). This work was also supported by postdoctoral fellowship from NIH (Award \#76146) (to DD-J). The content is solely the responsibility of the authors and does not necessarily represent the official views of the National Institutes of Health.

\section{ACKNOWLEDGMENTS}

We sincerely thank Carl Bortner and Robert Oakley for suggestions during manuscript preparation. All the figures were created with BioRender.com. 


\section{REFERENCES}

1. Oakley RH, Cidlowski JA. The Biology of the Glucocorticoid Receptor: New Signaling Mechanisms in Health and Disease. J Allergy Clin Immunol (2013) 132:1033-44. doi: 10.1016/j.jaci.2013.09.007

2. Zen M, Canova M, Campana C, Bettio S, Nalotto L, Rampudda M, et al. The Kaleidoscope of Glucorticoid Effects on Immune System. Autoimmun Rev (2011) 10:305-10. doi: 10.1016/j.autrev.2010.11.009

3. John S, Sabo PJ, Thurman RE, Sung MH, Biddie SC, Johnson TA, et al. Chromatin Accessibility Pre-Determines Glucocorticoid Receptor Binding Patterns. Nat Genet (2011) 43:264-8. doi: 10.1038/ng.759

4. Cohen DM, Steger DJ. Nuclear Receptor Function Through Genomics: Lessons From the Glucocorticoid Receptor. Trends Endocrinol Metab (2017) 28:531-40. doi: 10.1016/j.tem.2017.04.001

5. Lim HW, Uhlenhaut NH, Rauch A, Weiner J, Hubner S, Hubner N, et al. Genomic Redistribution of GR Monomers and Dimers Mediates Transcriptional Response to Exogenous Glucocorticoid In Vivo. Genome Res (2015) 25:836-44. doi: 10.1101/gr.188581.114

6. Uhlenhaut NH, Barish GD, Yu RT, Downes M, Karunasiri M, Liddle C, et al. Insights Into Negative Regulation by the Glucocorticoid Receptor From Genome-Wide Profiling of Inflammatory Cistromes. Mol Cell (2013) 49:158-71. doi: 10.1016/j.molcel.2012.10.013

7. Vettorazzi S, Bode C, Dejager L, Frappart L, Shelest E, Klassen C, et al. Glucocorticoids Limit Acute Lung Inflammation in Concert With Inflammatory Stimuli by Induction of Sphk1. Nat Commun (2015) 6:7796. doi: $10.1038 /$ ncomms 8796

8. Greulich F, Wierer M, Mechtidou A, Gonzalez-Garcia O, Uhlenhaut NH. The Glucocorticoid Receptor Recruits the COMPASS Complex to Regulate Inflammatory Transcription At Macrophage Enhancers. Cell Rep (2021) 34:108742. doi: 10.1016/j.celrep.2021.108742

9. Imai E, Miner JN, Mitchell JA, Yamamoto KR, Granner DK. Glucocorticoid receptor-cAMP Response Element-Binding Protein Interaction and the Response of the Phosphoenolpyruvate Carboxykinase Gene to Glucocorticoids. J Biol Chem (1993) 268:5353-6. doi: 10.1016/S0021-9258(18)53327-5

10. Surjit M, Ganti KP, Mukherji A, Ye T, Hua G, Metzger D, et al. Widespread Negative Response Elements Mediate Direct Repression by AgonistLiganded Glucocorticoid Receptor. Cell (2011) 145:224-41. doi: 10.1016/ j.cell.2011.03.027

11. Hudson WH, Youn C, Ortlund EA. The Structural Basis of Direct Glucocorticoid-Mediated Transrepression. Nat Struct Mol Biol (2013) 20:53-8. doi: 10.1038/nsmb.2456

12. Cain DW, Cidlowski JA. Immune Regulation by Glucocorticoids. Nat Rev Immunol (2017) 17:233-47. doi: 10.1038/nri.2017.1

13. Desmet SJ, De Bosscher K. Glucocorticoid Receptors: Finding the Middle Ground. J Clin Invest (2017) 127:1136-45. doi: 10.1172/JCI88886

14. Frijters R, Fleuren W, Toonen EJ, Tuckermann JP, Reichardt HM, van der Maaden H, et al. Prednisolone-Induced Differential Gene Expression in Mouse Liver Carrying Wild Type or a Dimerization-Defective Glucocorticoid Receptor. BMC Genomics (2010) 11:359. doi: 10.1186/ 1471-2164-11-359

15. Schiller BJ, Chodankar R, Watson LC, Stallcup MR, Yamamoto KR. Glucocorticoid Receptor Binds Half Sites as a Monomer and Regulates Specific Target Genes. Genome Biol (2014) 15:418. doi: 10.1186/s13059-0140418-y

16. John S, Sabo PJ, Johnson TA, Sung MH, Biddie SC, Lightman SL, et al. Interaction of the Glucocorticoid Receptor With the Chromatin Landscape. Mol Cell (2008) 29:611-24. doi: 10.1016/j.molcel.2008.02.010

17. Oh KS, Patel H, Gottschalk RA, Lee WS, Baek S, Fraser IDC, et al. AntiInflammatory Chromatinscape Suggests Alternative Mechanisms of Glucocorticoid Receptor Action. Immunity (2017) 47:298-309.e5. doi: 10.1016/j.immuni.2017.07.012

18. Sasse SK, Gruca M, Allen MA, Kadiyala V, Song T, Gally F, et al. Nascent Transcript Analysis of Glucocorticoid Crosstalk With TNF Defines Primary and Cooperative Inflammatory Repression. Genome Res (2019) 29:1753-65. doi: 10.1101/gr.248187.119

19. Busillo JM, Azzam KM, Cidlowski JA. Glucocorticoids Sensitize the Innate Immune System Through Regulation of the NLRP3 Inflammasome. J Biol Chem (2011) 286:38703-13. doi: 10.1074/jbc.M111.275370
20. Lannan EA, Galliher-Beckley AJ, Scoltock AB, Cidlowski JA. Proinflammatory Actions of Glucocorticoids: Glucocorticoids and TNFalpha Coregulate Gene Expression In Vitro and In Vivo. Endocrinology (2012) 153:3701-12. doi: 10.1210/en.2012-1020

21. Diaz-Jimenez D, Petrillo MG, Busada JT, Hermoso MA, Cidlowski JA. Glucocorticoids Mobilize Macrophages by Transcriptionally Up-Regulating the Exopeptidase DPP4. J Biol Chem (2020) 295:3213-27. doi: 10.1074/ jbc.RA119.010894

22. van de Garde MD, Martinez FO, Melgert BN, Hylkema MN, Jonkers RE, Hamann J. Chronic Exposure to Glucocorticoids Shapes Gene Expression and Modulates Innate and Adaptive Activation Pathways in Macrophages With Distinct Changes in Leukocyte Attraction. J Immunol (2014) 192:1196-208. doi: 10.4049/jimmunol.1302138

23. Ishiguro Y, Ohkawara T, Sakuraba H, Yamagata K, Hiraga H, Yamaguchi S, et al. Macrophage Migration Inhibitory Factor has a Proinflammatory Activity Via the p38 Pathway in Glucocorticoid-Resistant Ulcerative Colitis. Clin Immunol (2006) 120:335-41. doi: 10.1016/j.clim.2006.05.010

24. Merad M, Manz MG, Karsunky H, Wagers A, Peters W, Charo I, et al. Langerhans Cells Renew in the Skin Throughout Life Under Steady-State Conditions. Nat Immunol (2002) 3:1135-41. doi: 10.1038/ni852

25. Yona S, Kim KW, Wolf Y, Mildner A, Varol D, Breker M, et al. Fate Mapping Reveals Origins and Dynamics of Monocytes and Tissue Macrophages Under Homeostasis. Immunity (2013) 38:79-91. doi: 10.1016/j.immuni.2012.12.001

26. Tamoutounour S, Guilliams M, Montanana Sanchis F, Liu H, Terhorst D, Malosse C, et al. Origins and Functional Specialization of Macrophages and of Conventional and Monocyte-Derived Dendritic Cells in Mouse Skin. Immunity (2013) 39:925-38. doi: 10.1016/j.immuni.2013.10.004

27. Bain CC, Bravo-Blas A, Scott CL, Perdiguero EG, Geissmann F, Henri S, et al. Constant Replenishment From Circulating Monocytes Maintains the Macrophage Pool in the Intestine of Adult Mice. Nat Immunol (2014) 15:929-37. doi: 10.1038/ni.2967

28. Epelman S, Lavine KJ, Beaudin AE, Sojka DK, Carrero JA, Calderon B, et al. Embryonic and Adult-Derived Resident Cardiac Macrophages are Maintained Through Distinct Mechanisms At Steady State and During Inflammation. Immunity (2014) 40:91-104. doi: 10.1016/j. immuni.2013.11.019

29. Weinberger T, Esfandyari D, Messerer D, Percin G, Schleifer C, Thaler R, et al. Ontogeny of Arterial Macrophages Defines Their Functions in Homeostasis and Inflammation. Nat Commun (2020) 11:4549. doi: $10.1038 / \mathrm{s} 41467-020-18287-\mathrm{x}$

30. Martinez FO, Gordon S, Locati M, Mantovani A. Transcriptional Profiling of the Human Monocyte-to-Macrophage Differentiation and Polarization: New Molecules and Patterns of Gene Expression. J Immunol (2006) 177:7303-11. doi: 10.4049/jimmunol.177.10.7303

31. Wynn TA, Vannella KM. Macrophages in Tissue Repair, Regeneration, and Fibrosis. Immunity (2016) 44:450-62. doi: 10.1016/j.immuni.2016.02.015

32. Li Z, Xiao J, Xu X, Li W, Zhong R, Qi L, et al. M-Csf, IL-6, and TGF-beta Promote Generation of a New Subset of Tissue Repair Macrophage for Traumatic Brain Injury Recovery. Sci $A d v$ (2021) 7:11. doi: 10.1126/ sciadv.abb6260

33. Teitelbaum SL, Malone JD, Kahn AJ. Glucocorticoid Enhancement of Bone Resorption by Rat Peritoneal Macrophages In Vitro. Endocrinology (1981) 108:795-9. doi: 10.1210/endo-108-3-795

34. Galuppo P, Vettorazzi S, Hovelmann J, Scholz CJ, Tuckermann JP, Bauersachs J, et al. The Glucocorticoid Receptor in Monocyte-Derived Macrophages is Critical for Cardiac Infarct Repair and Remodeling. FASEB J (2017) 31:5122-32. doi: 10.1096/fj.201700317R

35. Meers GK, Bohnenberger H, Reichardt HM, Luhder F, Reichardt SD. Impaired Resolution of DSS-induced Colitis in Mice Lacking the Glucocorticoid Receptor in Myeloid Cells. PloS One (2018) 13:e0190846. doi: 10.1371/journal.pone. 0190846

36. Valbuena Perez JV, Linnenberger R, Dembek A, Bruscoli S, Riccardi C, Schulz MH, et al. Altered Glucocorticoid Metabolism Represents a Feature of Macroph-Aging. Aging Cell (2020) 19:e13156. doi: 10.1111/acel.13156

37. Ren R, Oakley RH, Cruz-Topete D, Cidlowski JA. Dual Role for Glucocorticoids in Cardiomyocyte Hypertrophy and Apoptosis. Endocrinology (2012) 153:5346-60. doi: 10.1210/en.2012-1563 
38. Oakley RH, Ren R, Cruz-Topete D, Bird GS, Myers PH, Boyle MC, et al. Essential Role of Stress Hormone Signaling in Cardiomyocytes for the Prevention of Heart Disease. Proc Natl Acad Sci U S A (2013) 110:1703540. doi: $10.1073 /$ pnas. 1302546110

39. Oakley RH, Cruz-Topete D, He B, Foley JF, Myers PH, Xu X, et al. Cardiomyocyte Glucocorticoid and Mineralocorticoid Receptors Directly and Antagonistically Regulate Heart Disease in Mice. Sci Signal (2019) 12:577. doi: 10.1126/scisignal.aau9685

40. Frantz S, Nahrendorf M. Cardiac Macrophages and Their Role in Ischaemic Heart Disease. Cardiovasc Res (2014) 102:240-8. doi: 10.1093/cvr/cvu025

41. Hulsmans M, Sam F, Nahrendorf M. Monocyte and Macrophage Contributions to Cardiac Remodeling. J Mol Cell Cardiol (2016) 93:14955. doi: 10.1016/j.yjmcc.2015.11.015

42. Trevor Glaros ML, Li L. Macrophages and Fibroblasts During Inflammation, Tissue Damage and Organ Injury. Front Bioscience (2009) 14:3988-93. doi: $10.2741 / 3506$

43. Simoes FC, Cahill TJ, Kenyon A, Gavriouchkina D, Vieira JM, Sun X, et al. Macrophages Directly Contribute Collagen to Scar Formation During Zebrafish Heart Regeneration and Mouse Heart Repair. Nat Commun (2020) 11:600. doi: 10.1038/s41467-019-14263-2

44. Dick SA, Macklin JA, Nejat S, Momen A, Clemente-Casares X, Althagafi MG, et al. Self-Renewing Resident Cardiac Macrophages Limit Adverse Remodeling Following Myocardial Infarction. Nat Immunol (2019) 20:2939. doi: 10.1038/s41590-018-0272-2

45. Chakarov S, Lim HY, Tan L, Lim SY, See P, Lum J, et al. Two Distinct Interstitial Macrophage Populations Coexist Across Tissues in Specific Subtissular Niches. Science (2019) 363:6432. doi: 10.1126/science.aau0964

46. Hulsmans M, Clauss S, Xiao L, Aguirre AD, King KR, Hanley A, et al. Macrophages Facilitate Electrical Conduction in the Heart. Cell (2017) 169:510-22.e20. doi: 10.1016/j.cell.2017.03.050

47. Nicolas-Avila JA, Lechuga-Vieco AV, Esteban-Martinez L, Sanchez-Diaz M, Diaz-Garcia E, Santiago DJ, et al. A Network of Macrophages Supports Mitochondrial Homeostasis in the Heart. Cell (2020) 183:94-109.e23. doi: 10.1016/j.cell.2020.08.031

48. Adomati T, Cham LB, Hamdan TA, Bhat H, Duhan V, Li F, et al. Dead Cells Induce Innate Anergy Via Mertk After Acute Viral Infection. Cell Rep (2020) 30:3671-3681 e5. doi: 10.1016/j.celrep.2020.02.101

49. McColl A, Bournazos S, Franz S, Perretti M, Morgan BP, Haslett C, et al. Glucocorticoids Induce Protein S-dependent Phagocytosis of Apoptotic Neutrophils by Human Macrophages. J Immunol (2009) 183:2167-75. doi: 10.4049/jimmunol.0803503

50. Tentillier N, Etzerodt A, Olesen MN, Rizalar FS, Jacobsen J, Bender D, et al. Anti-Inflammatory Modulation of Microglia Via CD163-Targeted Glucocorticoids Protects Dopaminergic Neurons in the 6-OHDA Parkinson's Disease Model. J Neurosci (2016) 36:9375-90. doi: 10.1523/ JNEUROSCI.1636-16.2016

51. Tertil M, Skupio U, Barut J, Dubovyk V, Wawrzczak-Bargiela A, Soltys Z, et al. Glucocorticoid Receptor Signaling in Astrocytes is Required for Aversive Memory Formation. Transl Psychiatry (2018) 8:255. doi: 10.1038/ s41398-018-0300-x

52. Skupio U, Tertil M, Bilecki W, Barut J, Korostynski M, Golda S, et al. Astrocytes Determine Conditioned Response to Morphine Via Glucocorticoid Receptor-Dependent Regulation of Lactate Release. Neuropsychopharmacology (2020) 45:404-15. doi: 10.1038/s41386-019-0450-4

53. Williams S, Ghosh C. Neurovascular Glucocorticoid Receptors and Glucocorticoids: Implications in Health, Neurological Disorders and Drug Therapy. Drug Discovery Today (2020) 25:89-106. doi: 10.1016/ j.drudis.2019.09.009

54. Gomez-Sanchez E, Gomez-Sanchez CE. The Multifaceted Mineralocorticoid Receptor. Compr Physiol (2014) 4:965-94. doi: 10.1002/cphy.c130044

55. Fietta P, Fietta P, Delsante G. Central Nervous System Effects of Natural and Synthetic Glucocorticoids. Psychiatry Clin Neurosci (2009) 63:613-22. doi: 10.1111/j.1440-1819.2009.02005.x

56. Fitzsimons CP, van Hooijdonk LW, Schouten M, Zalachoras I, Brinks V, Zheng T, et al. Knockdown of the Glucocorticoid Receptor Alters Functional Integration of Newborn Neurons in the Adult Hippocampus and Impairs Fear-Motivated Behavior. Mol Psychiatry (2013) 18:993-1005. doi: 10.1038/ mp.2012.123
57. Scheimann JR, Mahbod P, Morano R, Frantz L, Packard B, Campbell K, et al. Deletion of Glucocorticoid Receptors in Forebrain Gabaergic Neurons Alters Acute Stress Responding and Passive Avoidance Behavior in Female Mice. Front Behav Neurosci (2018) 12:325. doi: 10.3389/fnbeh.2018.00325

58. Joëls M, .de Kloet ER. Control of Neuronal Excitability by Corticosteroid Hormones. TINS (1992) 15(1):25-30. doi: 10.1016/0166-2236(92)90345-9

59. Viho EMG, Buurstede JC, Mahfouz A, Koorneef LL, van Weert L, Houtman $\mathrm{R}$, et al. Corticosteroid Action in the Brain: The Potential of Selective Receptor Modulation. Neuroendocrinology (2019) 109:266-76. doi: $10.1159 / 000499659$

60. Anacker C, Cattaneo A, Luoni A, Musaelyan K, Zunszain PA, Milanesi E, et al. Glucocorticoid-Related Molecular Signaling Pathways Regulating Hippocampal Neurogenesis. Neuropsychopharmacology (2013) 38:872-83. doi: $10.1038 /$ npp. 2012.253

61. Gage FH. Adult Neurogenesis in Mammals. Science (2019) 364:827-8. doi: 10.1126/science.aav6885

62. Seo DO, Carillo MA, Chih-Hsiung Lim S, Tanaka KF, Drew MR. Adult Hippocampal Neurogenesis Modulates Fear Learning Through Associative and Nonassociative Mechanisms. J Neurosci (2015) 35:11330-45. doi: 10.1523/JNEUROSCI.0483-15.2015

63. Epp JR, Silva Mera R, Kohler S, Josselyn SA, Frankland PW. NeurogenesisMediated Forgetting Minimizes Proactive Interference. Nat Commun (2016) 7:10838. doi: $10.1038 /$ ncomms 10838

64. Anacker C, Hen R. Adult Hippocampal Neurogenesis and Cognitive Flexibility - Linking Memory and Mood. Nat Rev Neurosci (2017) 18:33546. doi: 10.1038/nrn.2017.45

65. Dranovsky A, Hen R. Hippocampal Neurogenesis: Regulation by Stress and Antidepressants. Biol Psychiatry (2006) 59:1136-43. doi: 10.1016/ j.biopsych.2006.03.082

66. Lehmann ML, Brachman RA, Martinowich K, Schloesser RJ, Herkenham M. Glucocorticoids Orchestrate Divergent Effects on Mood Through Adult Neurogenesis. J Neurosci (2013) 33:2961-72. doi: 10.1523/JNEUROSCI. 3878-12.2013

67. Furay AR, Bruestle AE, Herman JP. The Role of the Forebrain Glucocorticoid Receptor in Acute and Chronic Stress. Endocrinology (2008) 149:5482-90. doi: 10.1210/en.2008-0642

68. Quarta C, Clemmensen C, Zhu Z, Yang B, Joseph SS, Lutter D, et al. Molecular Integration of Incretin and Glucocorticoid Action Reverses Immunometabolic Dysfunction and Obesity. Cell Metab (2017) 26:620-32.e6. doi: 10.1016/j.cmet.2017.08.023

69. Shiraishi D, Fujiwara Y, Komohara Y, Mizuta H, Takeya M. Glucagon-Like Peptide-1 (GLP-1) Induces M2 Polarization of Human Macrophages Via STAT3 Activation. Biochem Biophys Res Commun (2012) 425:304-8. doi: 10.1016/j.bbrc.2012.07.086

70. Yang L, Chen L, Li D, Xu H, Chen J, Min X, et al. Effect of GLP-1/GLP-1R on the Polarization of Macrophages in the Occurrence and Development of Atherosclerosis. Mediators Inflamm (2021) 2021:5568159. doi: 10.1155/ 2021/5568159

71. Block ML, Zecca L, Hong JS. Microglia-Mediated Neurotoxicity: Uncovering the Molecular Mechanisms. Nat Rev Neurosci (2007) 8:57-69. doi: 10.1038/ nrn2038

72. Hanisch UK, Kettenmann H. Microglia: Active Sensor and Versatile Effector Cells in the Normal and Pathologic Brain. Nat Neurosci (2007) 10:1387-94. doi: $10.1038 / \mathrm{nn} 1997$

73. Neumann H, Kotter MR, Franklin RJ. Debris Clearance by Microglia: An Essential Link Between Degeneration and Regeneration. Brain (2009) 132:288-95. doi: 10.1093/brain/awn109

74. Frank MG, Thompson BM, Watkins LR, Maier SF. Glucocorticoids Mediate Stress-Induced Priming of Microglial Pro-Inflammatory Responses. Brain Behav Immun (2012) 26:337-45. doi: 10.1016/j.bbi.2011.10.005

75. Wolf Y, Yona S, Kim KW, Jung S. Microglia, Seen From the CX3CR1 Angle. Front Cell Neurosci (2013) 7:26. doi: 10.3389/fncel.2013.00026

76. Lynch MA. The Multifaceted Profile of Activated Microglia. Mol Neurobiol (2009) 40:139-56. doi: 10.1007/s12035-009-8077-9

77. Gehrmann J, Banati RB, Kreutzberg GW. Microglia in the Immune Surveillance of the Brain: Human Microglia Constitutively Express HLADR Molecules. J Neuroimmunology (1993) 48:189-98. doi: 10.1016/01655728(93)90191-Z 
78. Bernier LP, York EM, Kamyabi A, Choi HB, Weilinger NL, MacVicar BA. Microglial Metabolic Flexibility Supports Immune Surveillance of the Brain Parenchyma. Nat Commun (2020) 11:1559. doi: 10.1038/s41467-020-15267-z

79. Aarum J, Sandberg K, Haeberlein SL, Persson MA. Migration and Differentiation of Neural Precursor Cells can be Directed by Microglia. Proc Natl Acad Sci U S A (2003) 100:15983-8. doi: 10.1073/ pnas. 2237050100

80. Polazzi E, Contestabile A. Neuron-Conditioned Media Differentially Affect the Survival of Activated or Unstimulated Microglia: Evidence for Neuronal Control on Apoptotic Elimination of Activated Microglia. J Neuropathol Exp Neurol (2003) 62:351-62. doi: 10.1093/jnen/62.4.351

81. Wang C, Yue H, Hu Z, Shen Y, Ma J, Li J, et al. Microglia Mediate Forgetting Via Complement-Dependent Synaptic Elimination. Science (2020) 367:68894. doi: $10.1126 /$ science.aaz2288

82. De Lucia C, Rinchon A, Olmos-Alonso A, Riecken K, Fehse B, Boche D, et al. Microglia Regulate Hippocampal Neurogenesis During Chronic Neurodegeneration. Brain Behav Immun (2016) 55:179-90. doi: 10.1016/ j.bbi.2015.11.001

83. Biber K, Neumann H, Inoue K, Boddeke HW. Neuronal 'On' and 'Off' Signals Control Microglia. Trends Neurosci (2007) 30:596-602. doi: 10.1016/ j.tins.2007.08.007

84. Diaz-Aparicio I, Paris I, Sierra-Torre V, Plaza-Zabala A, Rodriguez-Iglesias N, Marquez-Ropero M, et al. Microglia Actively Remodel Adult Hippocampal Neurogenesis Through the Phagocytosis Secretome. J Neurosci (2020) 40:1453-82. doi: 10.1523/JNEUROSCI.0993-19.2019

85. Pocock JM, Kettenmann H. Neurotransmitter Receptors on Microglia. Trends Neurosci (2007) 30:527-35. doi: 10.1016/j.tins.2007.07.007

86. Carrillo-de Sauvage MA, Maatouk L, Arnoux I, Pasco M, Sanz Diez A, Delahaye M, et al. Potent and Multiple Regulatory Actions of Microglial Glucocorticoid Receptors During CNS Inflammation. Cell Death Differ (2013) 20:1546-57. doi: 10.1038/cdd.2013.108

87. Maatouk L, Compagnion AC, Sauvage MC, Bemelmans AP, Leclere-Turbant S, Cirotteau V, et al. TLR9 Activation Via Microglial Glucocorticoid Receptors Contributes to Degeneration of Midbrain Dopamine Neurons. Nat Commun (2018) 9:2450. doi: 10.1038/s41467-018-04569-y

88. Grainger JR, Konkel JE, Zangerle-Murray T, Shaw TN. Macrophages in Gastrointestinal Homeostasis and Inflammation. Pflugers Arch (2017) 469:527-39. doi: 10.1007/s00424-017-1958-2

89. Nakagaki BN, Vieira AT, Rezende RM, David BA, Menezes GB. Tissue Macrophages as Mediators of a Healthy Relationship With Gut Commensal Microbiota. Cell Immunol (2018) 330:16-26. doi: 10.1016/j. cellimm.2018.01.017

90. Hine AM, Loke P. Intestinal Macrophages in Resolving Inflammation. J Immunol (2019) 203:593-9. doi: 10.4049/jimmunol.1900345

91. Maeda K, Nagashima R, Imai Y, Takahashi T. Lamina Propria Macrophages in the Human Gastrointestinal Mucosa- Their Distribution, Immunohistological Phenotype, and Function. J Histochem Cytochem (1996) 44:721-31. doi: 10.1177/44.7.8675993

92. Mowat AM, Agace WW. Regional Specialization Within the Intestinal Immune System. Nat Rev Immunol (2014) 14:667-85. doi: 10.1038/nri3738

93. Shaw TN, Houston SA, Wemyss K, Bridgeman HM, Barbera TA, ZangerleMurray T, et al. Tissue-Resident Macrophages in the Intestine are Long Lived and Defined by Tim-4 and CD4 Expression. J Exp Med (2018) 215:1507-18. doi: 10.1084/jem.20180019

94. De Schepper S, Verheijden S, Aguilera-Lizarraga J, Viola MF, Boesmans W, Stakenborg N, et al. Self-Maintaining Gut Macrophages Are Essential for Intestinal Homeostasis. Cell (2018) 175:400-15.e13. doi: 10.1016/ j.cell.2018.07.048

95. Zigmond E, Bernshtein B, Friedlander G, Walker CR, Yona S, Kim KW, et al. Macrophage-Restricted interleukin-10 Receptor Deficiency, But Not IL-10 Deficiency, Causes Severe Spontaneous Colitis. Immunity (2014) 40:720-33. doi: 10.1016/j.immuni.2014.03.012

96. Ford AC, Sandborn WJ, Khan KJ, Hanauer SB, Talley NJ, Moayyedi P. Efficacy of Biological Therapies in Inflammatory Bowel Disease: Systematic Review and Meta-Analysis. Am J Gastroenterol (2011) 106:644-59. doi: 10.1038/ajg.2011.73

97. Thiesen A, Wild GE, Keelan M, Clandinin MT, Thomson AB. Locally and Systemically Active Glucocorticosteroids Modify Intestinal Absorption of
Sugars in Rats. J Appl Physiol (1985) (2003) 94:583-90. doi: 10.1152/ japplphysiol.00134.2002

98. Thiesen A, Wild GE, Tappenden KA, Drozdowski L, Keelan M, Thomson BK, et al. The Locally Acting Glucocorticosteroid Budesonide Enhances Intestinal Sugar Uptake Following Intestinal Resection in Rats. Gut (2003) 52:252-9. doi: $10.1136 /$ gut.52.2.252

99. Reichardt SD, Foller M, Rexhepaj R, Pathare G, Minnich K, Tuckermann JP, et al. Glucocorticoids Enhance Intestinal Glucose Uptake Via the Dimerized Glucocorticoid Receptor in Enterocytes. Endocrinology (2012) 153:1783-94. doi: 10.1210/en.2011-1747

100. Reichardt SD, Weinhage T, Rotte A, Foller M, Oppermann M, Luhder F, et al. Glucocorticoids Induce Gastroparesis in Mice Through Depletion of LArginine. Endocrinology (2014) 155:3899-908. doi: 10.1210/en.2014-1246

101. Cipriani G, Gibbons SJ, Kashyap PC, Farrugia G. Intrinsic Gastrointestinal Macrophages: Their Phenotype and Role in Gastrointestinal Motility. Cell Mol Gastroenterol Hepatol (2016) 2:120-130 el. doi: 10.1016/j.jcmgh.2016.01.003

102. Busada JT, Ramamoorthy S, Cain DW, Xu X, Cook DN, Cidlowski JA. Endogenous Glucocorticoids Prevent Gastric Metaplasia by Suppressing Spontaneous Inflammation. J Clin Invest (2019) 129:1345-58. doi: 10.1172/ JCI123233

103. Cima I, Corazza N, Dick B, Fuhrer A, Herren S, Jakob S, et al. Intestinal Epithelial Cells Synthesize Glucocorticoids and Regulate T Cell Activation. J Exp Med (2004) 200:1635-46. doi: 10.1084/jem.20031958

104. Mueller M, Cima I, Noti M, Fuhrer A, Jakob S, Dubuquoy L, et al. The Nuclear Receptor LRH-1 Critically Regulates Extra-Adrenal Glucocorticoid Synthesis in the Intestine. J Exp Med (2006) 203:2057-62. doi: 10.1084/ jem.20060357

105. Bayrer JR, Wang H, Nattiv R, Suzawa M, Escusa HS, Fletterick RJ, et al. LRH1 Mitigates Intestinal Inflammatory Disease by Maintaining Epithelial Homeostasis and Cell Survival. Nat Commun (2018) 9:4055. doi: 10.1038/ s41467-018-06137-w

106. Mueller KM, Themanns M, Friedbichler K, Kornfeld JW, Esterbauer H, Tuckermann JP, et al. Hepatic Growth Hormone and Glucocorticoid Receptor Signaling in Body Growth, Steatosis and Metabolic Liver Cancer Development. Mol Cell Endocrinol (2012) 361:1-11. doi: 10.1016/ j.mce.2012.03.026

107. Bose SK, Hutson I, Harris CA. Hepatic Glucocorticoid Receptor Plays a Greater Role Than Adipose GR in Metabolic Syndrome Despite Renal Compensation. Endocrinology (2016) 157:4943-60. doi: 10.1210/en.20161615

108. Quagliarini F, Mir AA, Balazs K, Wierer M, Dyar KA, Jouffe C, et al. Cistromic Reprogramming of the Diurnal Glucocorticoid Hormone Response by High-Fat Diet. Mol Cell (2019) 76:531-45.e5. doi: 10.1016/ j.molcel.2019.10.007

109. Kalvisa A, Siersbaek MS, Praestholm SM, Christensen LJL, Nielsen R, Stohr O, et al. Insulin Signaling and Reduced Glucocorticoid Receptor Activity Attenuate Postprandial Gene Expression in Liver. PloS Biol (2018) 16: e2006249. doi: 10.1371/journal.pbio.2006249

110. Tronche F, Opherk C, Moriggl R, Kellendonk C, Reimann A, Schwake L, et al. Glucocorticoid Receptor Function in Hepatocytes is Essential to Promote Postnatal Body Growth. Genes Dev (2004) 18:492-7. doi: 10.1101/gad.284704

111. Opherk C, Tronche F, Kellendonk C, Kohlmuller D, Schulze A, Schmid W, et al. Inactivation of the Glucocorticoid Receptor in Hepatocytes Leads to Fasting Hypoglycemia and Ameliorates Hyperglycemia in StreptozotocinInduced Diabetes Mellitus. Mol Endocrinol (2004) 18:1346-53. doi: 10.1210/ me.2003-0283

112. Quinn MA, Cidlowski JA. Endogenous Hepatic Glucocorticoid Receptor Signaling Coordinates Sex-Biased Inflammatory Gene Expression. FASEB J (2016) 30:971-82. doi: 10.1096/fj.15-278309

113. Zhou Z, Xu MJ, Gao B. Hepatocytes: A Key Cell Type for Innate Immunity. Cell Mol Immunol (2016) 13:301-15. doi: 10.1038/cmi.2015.97

114. Jenne CN, Kubes P. Immune Surveillance by the Liver. Nat Immunol (2013) 14:996-1006. doi: 10.1038/ni.2691

115. Karlmark KR, Weiskirchen R, Zimmermann HW, Gassler N, Ginhoux F, Weber C, et al. Hepatic Recruitment of the Inflammatory Gr1+ Monocyte Subset Upon Liver Injury Promotes Hepatic Fibrosis. Hepatology (2009) 50:261-74. doi: 10.1002/hep.22950 
116. Movita D, van de Garde MD, Biesta P, Kreefft K, Haagmans B, Zuniga E, et al. Inflammatory Monocytes Recruited to the Liver Within 24 Hours After Virus-Induced Inflammation Resemble Kupffer Cells But are Functionally Distinct. J Virol (2015) 89:4809-17. doi: 10.1128/JVI.03733-14

117. Holt MP, Cheng L, Ju C. Identification and Characterization of Infiltrating Macrophages in Acetaminophen-Induced Liver Injury. J Leukoc Biol (2008) 84:1410-21. doi: 10.1189/jlb.0308173

118. Robert O, Boujedidi H, Bigorgne A, Ferrere G, Voican CS, Vettorazzi S, et al. Decreased Expression of the Glucocorticoid receptor-GILZ Pathway in Kupffer Cells Promotes Liver Inflammation in Obese Mice. J Hepatol (2016) 64:916-24. doi: 10.1016/j.jhep.2015.11.023

119. Knolle P, Schlaak J, Uhrig A, Kempf P, Meyer zum Buschenfelde KH, Gerken G. Human Kupffer Cells Secrete IL-10 in Response to Lipopolysaccharide (LPS) Challenge. J Hepatol (1995) 22:226-9. doi: 10.1016/0168-8278(95) 80433-1

120. Santucci L, Fiorucci S, Chiorean M, Brunori PM, Di Matteo FM, Sidoni A, et al. Interleukin 10 Reduces Lethality and Hepatic Injury Induced by Lipopolysaccharide in Galactosamine-Sensitized Mice. Gastroenterology (1996) 111:736-44. doi: 10.1053/gast.1996.v111.pm8780580

121. Erhardt A, Biburger M, Papadopoulos T, Tiegs G. Il-10, Regulatory T Cells, and Kupffer Cells Mediate Tolerance in Concanavalin A-induced Liver Injury in Mice. Hepatology (2007) 45:475-85. doi: 10.1002/hep.21498

122. Heymann F, Peusquens J, Ludwig-Portugall I, Kohlhepp M, Ergen C, Niemietz P, et al. Liver Inflammation Abrogates Immunological Tolerance Induced by Kupffer Cells. Hepatology (2015) 62:279-91. doi: 10.1002/ hep. 27793

123. Mozo L, Suarez A, Gutierrez C. Glucocorticoids Up-Regulate Constitutive interleukin-10 Production by Human Monocytes. Clin Exp Allergy (2004) 34:406-12. doi: 10.1111/j.1365-2222.2004.01824.x

124. Marchant A, Amraoui Z, Gueydan C, Bruyns C, Le Moine O, Vandenabeele $\mathrm{P}$, et al. Methylprednisolone Differentially Regulates IL-10 and Tumour Necrosis Factor (TNF) Production During Murine Endotoxaemia. Clin Exp Immunol (1996) 106:91-6. doi: 10.1046/j.1365-2249.1996.d01-799.x

125. Kolios G, Valatas V, Kouroumalis E. Role of Kupffer Cells in the Pathogenesis of Liver Disease. World J Gastroenterol (2006) 12:7413-20. doi: 10.3748/wjg.v12.i46.7413
126. Kim KH, Lee JM, Zhou Y, Harpavat S, Moore DD. Glucocorticoids Have Opposing Effects on Liver Fibrosis in Hepatic Stellate and Immune Cells. Mol Endocrinol (2016) 30:905-16. doi: 10.1210/me.2016-1029

127. Melgert BN, Olinga P, Van Der Laan JM, Weert B, Cho J, Schuppan D, et al. Targeting Dexamethasone to Kupffer Cells: Effects on Liver Inflammation and Fibrosis in Rats. Hepatology (2001) 34:719-28. doi: 10.1053/ jhep.2001.27805

128. Rose KA, Holman NS, Green AM, Andersen ME, LeCluyse EL. Co-Culture of Hepatocytes and Kupffer Cells as an In Vitro Model of Inflammation and Drug-Induced Hepatotoxicity. J Pharm Sci (2016) 105:950-64. doi: 10.1016/ S0022-3549(15)00192-6

129. Dong L, Vaux DL. Glucocorticoids can Induce BIM to Trigger Apoptosis in the Absence of BAX and BAK1. Cell Death Dis (2020) 11:442. doi: 10.1038/ s41419-020-2599-5

130. Ploner C, Rainer J, Niederegger H, Eduardoff M, Villunger A, Geley S, et al. The BCL2 Rheostat in Glucocorticoid-Induced Apoptosis of Acute Lymphoblastic Leukemia. Leukemia (2008) 22:370-7. doi: 10.1038/ sj.leu.2405039

131. Bereshchenko O, Coppo M, Bruscoli S, Biagioli M, Cimino M, Frammartino T, et al. GILZ Promotes Production of Peripherally Induced Treg Cells and Mediates the Crosstalk Between Glucocorticoids and TGF-beta Signaling. Cell Rep (2014) 7:464-75. doi: 10.1016/j.celrep.2014.03.004

132. Proto JD, Doran AC, Subramanian M, Wang H, Zhang M, Sozen E, et al. Hypercholesterolemia Induces T Cell Expansion in Humanized Immune Mice. J Clin Invest (2018) 128:2370-5. doi: 10.1172/JCI97785

Conflict of Interest: The authors declare that the research was conducted in the absence of any commercial or financial relationships that could be construed as a potential conflict of interest.

Copyright (C) 2021 Diaz-Jimenez, Kolb and Cidlowski. This is an open-access article distributed under the terms of the Creative Commons Attribution License (CC BY). The use, distribution or reproduction in other forums is permitted, provided the original author(s) and the copyright owner(s) are credited and that the original publication in this journal is cited, in accordance with accepted academic practice. No use, distribution or reproduction is permitted which does not comply with these terms. 